\title{
PERAN POSITIVE EMOTION MEMEDIASI STORE ATMOSPHERE TERHADAP IMPULSE BUYING DI BEACHWALK KUTA BALI
}

\author{
Dewa Ayu Chandra Devi ${ }^{1}$ \\ I Nyoman Nurcaya ${ }^{2}$ \\ ${ }^{1,2}$ Fakultas Ekonomi dan Bisnis Universitas Udayana (Unud), Bali, Indonesia \\ email: D.A.chandradevi@gmail.com
}

\begin{abstract}
ABSTRAK
Pertumbuhan ritel di Indonesia kuartal pertama tahun 2019 mengalami peningkatan konsumsi karena bisa memanfaatkan event-event penting sehingga konsumen lebih mudah dalam melakukan Impulse buying. Tujuan dari penelitian ini adalah untuk mengetahui pengaruh store atmosphere terhadap positive emotion, pengaruh positive emotion terhadap impulse buying, pengaruh store atmosphere terhadap impulse buying dan peran positive emotion dalam memediasi pengaruh store atmosphere terhadap impulse buying di Beachwalk. Populasi dalam penelitian ini adalah semua orang yang berbelanja di Mall Beachwalk. Metode penentuan sampel yang digunakan dalam studi ini adalah dengan teknik purposive sampling yaitu teknik penentuan sampel dengan mempertimbangkan kriteria yang ditentukan oleh peneliti. Sampel yang dipilih dalam penelitian ini sebanyak 102 responden. Data dianalisis menggunakan teknik analisis jalur. Hasil penelitian menunjukkan bahwa store atmosphere berpengaruh positif dan signifikan terhadap positive emotion, positive emotion mempunyai pengaruh positif dan signifikan terhadap impulse buying. store atmosphere berpengaruh positif dan signifikan terhadap impulse buying. Positive emotion memediasi pengaruh store atmosphere terhadap impulse buying di Beachwalk
\end{abstract}

Kata kunci: Store atmosphere, Positive emotion, Impulse buying

\begin{abstract}
Retail growth in Indonesia in the first quarter of 2019 has increased consumption because it can take advantage of important events so that consumers are easier to do buying implements. The purpose of this study was to determine the effect of store atmosphere on positive emotion, the effect of positive emotion on impulse buying, the influence of store atmosphere on impulse buying and the role of positive emotion in mediating the effect of store atmosphere on impulse buying on Beachwalk. The population in this study were all those who shop at the Beachwalk Mall. The sampling method used in this study is the purposive sampling technique, which is the sampling technique by considering the criteria determined by the researcher. The samples chosen in this study were 102 respondents. Data were analyzed using path analysis techniques. The results showed that store atmosphere had a positive and significant effect on positive emotion, positive emotion had a positive and significant effect on impulse buying. Store atmosphere has a positive and significant effect on impulse buying. Positive emotion mediates the effect of store atmosphere on impulse buying on Beachwalk

Keywords: Store atmosphere, Positive emotion, Impulse buying
\end{abstract}




\section{PENDAHULUAN}

Perkembangan bisnis ritel di Indonesia tahun 2019 mengalami pertumbuhaan yang pesat. Pesatnya perkembangan ritel modern ini, berdasarkan pada keinginan perusahaan untuk memenuhi kebutuhan konsumennya (Sari dan Faisal, 2018). Pada kuartal pertama tahun 2019, pertumbuhan ritel di Indonesia mengalami peningkatan konsumsi dari tahun 2018 sekitar 7-8 persen yang meningkat pada tahun 2019 sekitar 10-15 persen karena banyak kegiatan jelang pemilu sehingga menyebabkan konsumsi masyarakat meningkat. Semakin banyak perusahaan ritel menyediakan barang-barang yang dibutuhkan konsumennya, maka konsumen akan terpenuhi kebutuhannya, hal ini merupakan strategi perusahaan ritel agar konsumen lebih mudah melakukan Impulse buying (Ompi dkk., 2018). Konsumen di Indonesia memang cenderung tidak memiliki rencana, sesuai dengan hasil riset yang dilakukan oleh lembaga Frontier Consulting Group mengungkapkan bahwa proses pembelian secara impulse buying atau yang tidak direncanakan di Indonesia relatif sangat tinggi, dibandingkan dengan konsumen di Amerika Serikat. Konsumen Indonesia memiliki proses pembelian impulsif sekitar 15 persen hingga 20 persen lebih tinggi (sumber: http://www.marketing.co.id/ dalam Aldhilla, 2014). Pernyataan tersebut didukung oleh hasil survei AC Nielsen mengenai perilaku pembelian konsumen di pusat pembelanjaan.

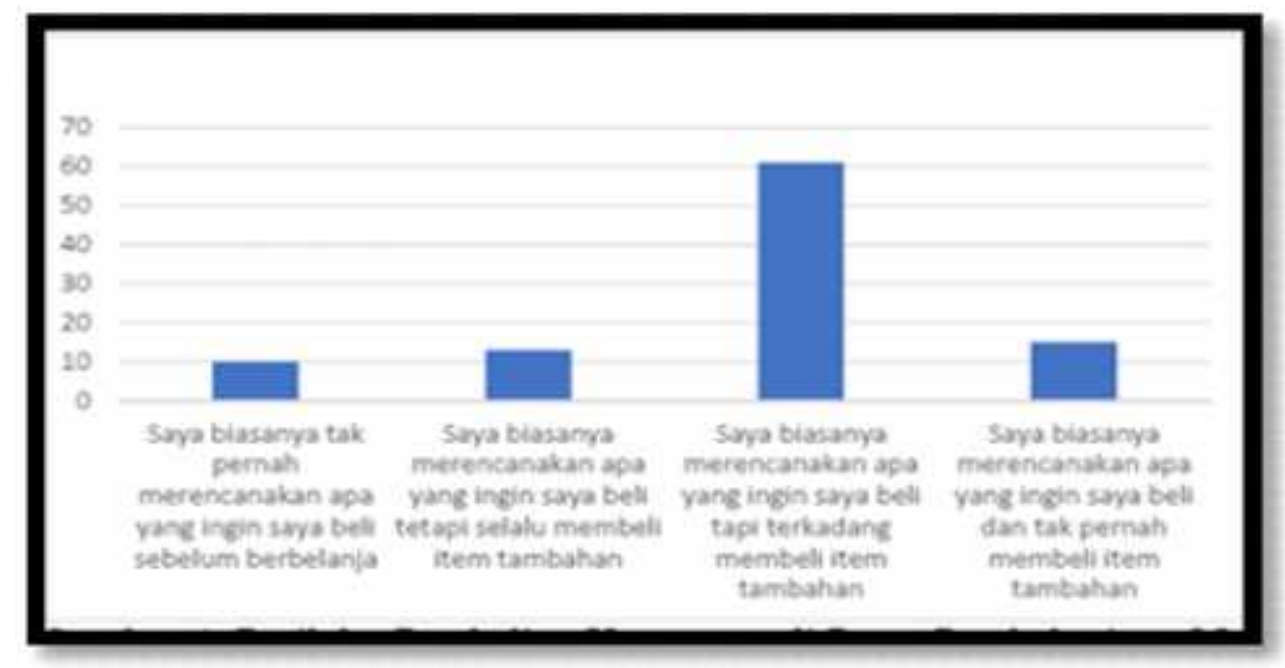

\section{Gambar 1. Perilaku Pembelian Konsumen di Pusat Pembelanjaan Modern}

Sumber: Survey AC Nielsen, 2015

Gambar 1. menunjukkan bahwa sebagian besar konsumen di Indonesia memiliki perilaku implusif terutama dalam membeli item tambahan yang tidak direncanakan. Dengan jumlah pusat perbelanjaan modern yang semakin banyak, diperkirakan perilaku impulse buying yang dilakukan konsumen juga akan mengalami peningkatan (Adiputra, 2015). Konsumen yang sudah terpenuhi kebutuhannya, nantinya akan melakukan Impulse buying saat melakukan pembelian suatu produk (Putra dan Mudiantono, 2014). Impulse buying dapat 
terjadi dimana saja dan kapan saja, maka sebuah gerai harus memperhatikan Store atmosphere, agar saat konsumen berbelanja di suatu toko, konsumen sekaligus dapat rekreasi (Dewi dan Giantari, 2015). Perilaku pembelian tidak terencana (Impulse buying) tersebut dipengaruhi oleh Store atmosphere sebuah toko sehingga dapat meninimbulkan Positive emotion yang dapat juga meningkatkan konsumen dalam melakukan Impulse buying.

Theory Of Reasoned Action dikembangkan oleh Ajzen dan Fishben. Secara sederhana teori ini mengatakan bahwa seseorang akan melakuan suatu tindakan, saat seseorang memandang bahwa tindakan tersebut dipandang positif dan percaya banyak orang ingin melakukan tindakan (Ajzen and Fisbhen, 2013).

Impulse buying adalah pembelian yang tidak direncenakan sebelumnya, pembelian tersebut adanya emosional seseorang saat berbelanja sehingga oarang tesebut melakukan pembelian secaa spontan dan pembeliannya berbeda dari yang telah direncanakan sebelumnya (Nurcaya dan Rastini, 2018). Jadi, Impulse buying adalah perilaku konsumen yang melakukan pembelian secara spontan, reflek, dan tak terduga, tanpa perencanaan sebelumnya.

Store atmosphere adalah keadaan toko yang meliputi komunikasi visual, pencahayaan, warna, musik, dan wangi-wangian untuk mempengaruhi opini pelanggan dan mempengaruhi pelanggan dalam melakukan pembelian suatu produk (Nofiawaty dan Yuliandi, 2014). Dampak dari lingkungan toko berlaku untuk setiap toko terkait pembelanjaan bahkan jika mereka tidak berada dalam industri ritel (S.B.Hearth, 2014). Dapat disimpulkan bahwa lingkungan toko (Store atmosphere) adalah karakteristik yang paling penting bagi setiap bisnis ritel karena Store atmosphere bertujuan untuk memenuhi persyaratan fungsional sambil melayani pengalaman berbelanja yang menyenangkan, sehingga mendukung pengambilan keputusan dalam berbelanja kosnumen (Nurcaya dan Rastini, 2018).

Emosi positif adalah suasana hati sesorang (bahagia, senang, dan gembira) yang dirasakan seseorang sehingga mempengaruhi pengambilan secara spontan terhadap suatu produk Leba (2015). Konsumen dengan positive emotion menunjukkan dorongan yang lebih besar dalam melakukan pembelian karena memiliki perasaan yamg tidak dibatasi oleh keadaan lingkungan sekitarnya, dan merasa lebih dihargai jika memiliki suatu barang yang dibeli tersebut (Andriyanto dkk., 2016). Emosi positif penting diteliti karena, Emosi positif itu sendiri perasaaan yang menyenangkan, yang menentukan intensitas berbelanja (Tirmizi et al., 2009).

Berdasarkan hasil penelitian terdahulu yang dilakukan oleh Winawati dan Saino (2015) menyatakan bahwa store atmosphere berpengaruh positif dan signifikan terhadap positive emotion. Penelitian lain yang berbeda yang dilakukan oleh Liaw (2007) store atmosphere berpengaruh negatif dan tidak signifikan terhadap emosi positif. Hasil penelitian Ahmad et al. (2019) menyatakan bahwa positive emotion berpengaruh positif dan signifikan terhadap impulse buying, sehingga semakin baik mood atau positive emotion yang dirasakan oleh konsumen semakin mudah konsumen tersebut melakukan Impulse buying. Penelitian lain yang berbeda yang dilakukan oleh Ismayuni dan Saraswati (2015) menyatakan bahwa emosi positif berpengaruh negatif dan tidak signifikan 
terhadap pembelian impulsif. Maulana (2018) menyatakan bahwa store atmosphere berpengaruh positif dan signifikan terhadap impulse buying. Penelitian lain yang dilakukan oleh Rahmadana (2016) menyatakan bahwa store atmosphere berpengaruh negatif dan tidak signifikan terhadap impulse buying. Hasil penelitian Negara dan Kusumadewi (2018) menyatakan bahwa emosi positif memediasi store atmosphere terhadap impulse buying. Penelitian lain yang berbeda dilakukan oleh Dewi dan Giantari (2015) menyatakan bahwa store atmosphere melalui positive emotion tidak signifikan berpengaruh terhadap impulse buying.

Berdasarkan identifikasi masalah, maka tujuan dari penelitian ini adalah untuk menjelaskan pengaruh store atmosphere terhadap positive emotion di Beachwalk, untuk menjelaskan pengaruh positive emotion terhadap impulse buying di Beachwalk, untuk menjelaskan pengaruh store atmosphere terhadap impulse buying di Beachwalk, dan untuk menjelaskan peran positive emotion memediasi pengaruh store atmosphere terhadap impulse buying di Beachwalk.

Penelitian yang dilakukan oleh Liaw (2007) Store atmosphere tidak mempengaruhi Emosi positif. Hal yang berbeda yang dilakukan oleh Hasanah et al. (2017) dalam penelitiannya menyatakan bahwa Store atmosphere berpengaruh positif signifikan terhadap Positive emotion. Penelitian tersebut sepemikiran dengan penelitian yang dilakukan oleh Asrinta (2018) menyatakan bahwa Store atmosphere dapat mempengaruhi Positive emotion secara signifikan, maka hipotesis sebagai berikut :

$\mathrm{H}_{1} \quad$ :store atmosphere berpengaruh positif dan signifikan terhadap positive emotion.

Penelitian yang dilakukan oleh Ismayuni dan Saraswati (2015) memperoleh hasil bahwa emosi positif tidak mempengaruhi impulse buying. Berbeda dengan penelitian yang dilakukan oleh Andani dan Wahyono (2018) menyatakan bahwa Positive emotion memiliki pengaruh positif terhadap impulse buying. Penelitian lain memperoleh hasil yang sama bahwa Emosi positif memiliki pengaruh positif terhadap impulse buying (Nindyakirana dan Maftukhah, 2016), maka hipotesis sebagai berikut :

$\mathrm{H}_{2}$ :positive emotion berpengaruh positif dan signifikan terhadap impulse buying.

Penelitian yang dilakukan oleh Rahmadana (2016) menyatakan bahwa Store atmosphere tidak berpengaruh terhadap impulse buying. Berbeda dengan hasil penelitian Dewi dan Giantari (2015) menyatakan bahwa Store atmosphere memeiliki pengaruh positif terhadap impulse buying. Penelitian sepemikiran dengan penelitian Maulana (2018) store atmosphere memiliki pengaruh positif terhadap impulse buying, maka hipotesis sebagai berikut :

$\mathrm{H}_{3} \quad$ :store atmosphere berpengaruh positif dan signifikan terhadap impulse buying.

Dewi dan Giantari (2015) dalam penelitiannya menunjukan bahwa positive emotion tidak mampu memediasi store atmosphere terhadap pembelian implusif. Berbeda dengan hasil penelitian yang dilakukan oleh Negara dan Kusumadewi (2018) menyatakan bahwa positive emotion mampu memediasi store atmosphere terhadap impulse buying. Margana dan Setiawan (2014) yang menyatakan bahwa 
Pembelian impulsif dipengaruhi oleh store atmosphere yang dimediasi oleh positive emotion.

Berdasarkan teori- teori dan penelitian yang ada dapat dirumuskan hipotesis bahwa:

$\mathrm{H}_{4} \quad$ :peran positive emotion memediasi secara signifikan pengaruh store atmosphere terhadap impulse buying.

Berdasarkan penelusuran pada kajian pustaka dan hasil-hasil penelitian sebelumnya maka model penelitian ini dapat digambarkan seperti Gambar 1 berikut :

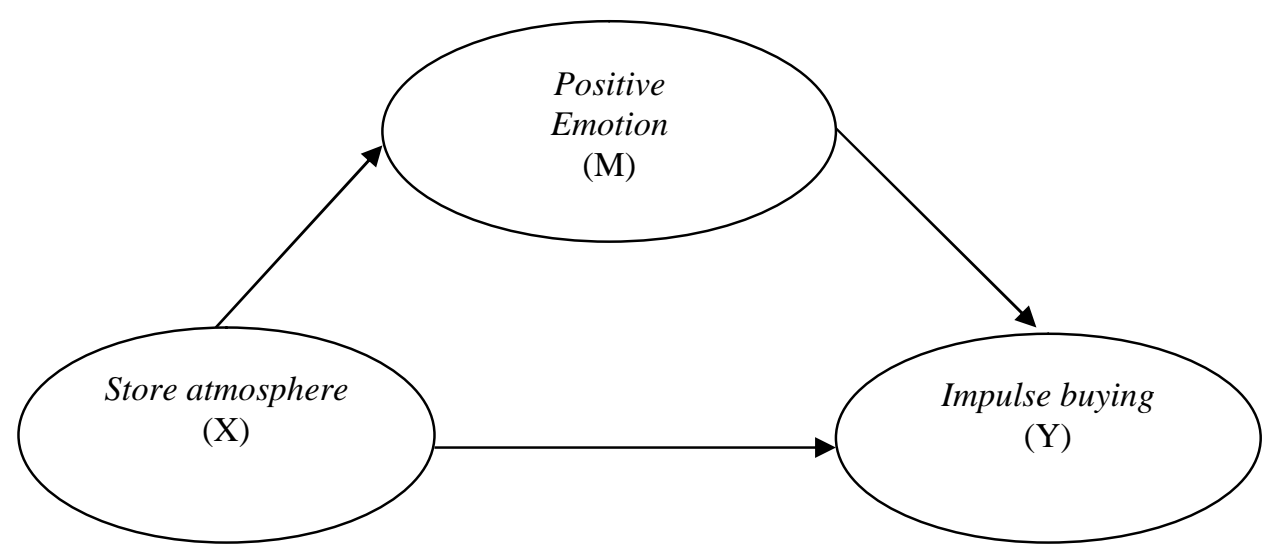

Gambar 2. Kerangka Konseptual

Sumber: Data Diolah, 2019

\section{METODE PENELITIAN}

Pendekatan yang digunakan pada penelitian ini adalah pendekatan kuantitatif yang berbentuk asosiatif. Penelitian ini dilakukan untuk menjelaskan hubungan pengaruh variabel store atmosphere dan positive emotion terhadap impulse buying di Beachwalk.

Lokasi penelitian adalah di Mall Beachwalk tertelak di Jl. Pantai kuta, Kuta, Badung, Bali. Penelitian ini menggunakan objek penelitian di Beachwalk, karena store atmosphere Beachwalk dengan konsep ramah lingkungan, sehingga bukan hanya untuk berbelanja namun sekaligus bisa menjadi tempat rekreasi bagi konsumen yang berkunjung di Beachwalk.Objek didalam penelitian berikut yaitu positive emotion memediasi store atmosphere terhadap impulse buying di Beachwalk, Kuta, Bali. Variabel bebas adalah store atmosphere (X), variabel mediasi adalah positive emotion (M) dan variabel dependennya yaitu impulse buying (Y). Jenis data kuantitatif serta kualitatif yang digunakan dalam penelitian berikut yaitu penilaian responden terhadap pernyataan-pernyataan yang diajukan dalam kuesioner, dan Data Survey oleh AC Nielsen (2015) tentang perilaku pembelian konsumen di pusat pembelanjaan modern serta skor jawaban kuesioner. Sumber data primer dan sekunder yang digunakan contohnya berupa hasil kuesioner atau jawaban dari responden yang memenuhi kriteria penelitian ini, dan Data Survey oleh AC Nielsen (2015) tentang perilaku pembelian konsumen di pusat pembelanjaan modern, serta penetuan skor jawaban kuesioner, 
serta penelitian terdahulu.

Populasi didalam penelitian ini yaitu semua orang yang berbelanja di Mall Beachwalk, Jl. Pantai Kuta, Badung, Bali. Metode penentuan sampel yang digunakan dalam penelitian ini adalah purposive sampling. Adapun kriteria yang digunakan dalam pemilihan sampel, yaitu: responden dengan usia 18-50 tahun, usia ini dipandang bisa memahami dengan baik pernyataan-pernyataan yang diajukan dalam kuesioner, pendidikan minimal SMA atau sederajat, mahasiswa dan pekerja, karena pada kelompok tersebut responden dianggap dapat memahami isi kuesioner dan menjawab kuesioner dengan baik, dan responden yang pernah berbelanja di Beachwalk, Kuta, Badung, Bali. Penelitian ini dianalisis dengan multivariatif dalam melakukan analisis, maka jumlah anggota sampel minimal 510 kali dari jumlah indikator yang akan diteliti (Sugiyono, 2014:129). Jumlah indikator yang akan digunakan digunakan berjumlah 17 indikator, maka ukuran sampelnya berkisar pada rentan 85-170 sampel. Berdasarkan pertimbangan tersebut, maka ukuran sampel penelitian ini ditetapkan sebanyak 102 responden.

Uji validitas bertujuan untuk mengetahui apakah instrumen pengujian yang digunakan dalam penelitian ini yakni kuesioner dikatakan valid. Apabila koefisien korelasi $\geq 0,30$ maka instrumen tersebut dapat dinyatakan valid (Sugiyono, 2016:126). Uji reliabilitas bertujuan untuk menguji instrumen penelitian yang digunakan, jadi berapa kali objek penelitian diuji dengan instrument penelitian, hasilnya akan tetap sama (Sugiyono, 2016:121). Instrumen penelitian dikatakan reliebel apabila metode Cornbach's Alpha 0,60 .

Pada penelitian ini digunakan teknik analisis data berupa teknik analisis jalur atau disebut sebagai Path Analysis merupakan perluasan penerapan analisis regresi linear berganda untuk memprediksi hubungan kausalitas antar variabel (model kausal) yang telah diterapkan sebelumnya berdasarkan teori. Menurut Utama (2016:162), langkah - langkah dalam anlaisis jalur yaitu sebagai berikut: merancang model, memeriksa pemenuhan asumsi, menduga parameter, memeriksa munculnya masalah identifikasi, memeriksa validitas model, dan interpretasi hasil.

\section{HASIL DAN PEMBAHASAN}

Beachwalk Kuta Bali merupakan jenis shopping mall yang saat ini merupakan salah satu mall yang sangat ramai dikunjungi setiap harinya. Mall ini berdiri sejak tahun 2012 dan kini menjadi salah satu mall paling ramai di Bali. Mall ini berlokasi di Jalan Pantai Kuta, sekitar 25 menit dari Bandara Ngurah Rai dan berada pada kawasan wisata dan area komersial di Pantai Kuta. Mall ini mulai beroperasi jam 09.00 WITA hingga 22.00 WITA dan buka setiap hari. Sementara untuk jam kerja kantor pengelola hanya pada hari senin sampai jumat mulai pukul 09.00 hingga pukul 18.00 WITA. Desain Beachwalk mengadopsi konsep semi indoor yang lebih menekankan konsep penataan landscape.

Karakteristik responden pada penelitian ini, dapat dilihat dari beberapa kriteria yaitu: jenis kelamin, umur, pendidikan terakhir, dan rata-rata pendapatan atau uang saku per bulan. Berikut disajikan karakteristik responden dari penelitian ini. 
Tabel 1.

Karakteristik Responden

\begin{tabular}{|c|c|c|c|c|}
\hline No. & Variabel & Klasifikasi & $\begin{array}{l}\text { Jumlah } \\
\text { (Orang) }\end{array}$ & Persentase \\
\hline \multirow[t]{3}{*}{1.} & Jenis Kelamin & Laki-laki & 40 & 39 \\
\hline & & Perempuan & 62 & 61 \\
\hline & & & 102 & 100 \\
\hline \multirow[t]{5}{*}{2.} & Usia (tahun) & $18-25$ & 101 & 99 \\
\hline & & $26-33$ & 1 & 1 \\
\hline & & $34-41$ & 0 & 0 \\
\hline & & $42-50$ & 0 & 0 \\
\hline & & & 102 & 100 \\
\hline \multirow[t]{5}{*}{3.} & Pendidikan & SMA & 86 & 84 \\
\hline & & Diploma & 3 & 3 \\
\hline & & S1 & 12 & 12 \\
\hline & & Lainnya & 1 & 1 \\
\hline & & & 102 & 100 \\
\hline \multirow[t]{6}{*}{4.} & Pekerjaan & Pelajar/Mahasiswa & 94 & 92 \\
\hline & & Pegawai Negeri & 1 & 1 \\
\hline & & Pegawai Swasta & 4 & 4 \\
\hline & & Wiraswasta & 1 & 1 \\
\hline & & Dan lain-lain & 2 & 2 \\
\hline & & & 102 & 100 \\
\hline
\end{tabular}

Sumber: Data diolah, 2019

Tabel 1. menunjukan bahwa responden yang berjenis kelamin laki-laki berjumlah 40 orang dengan persentase sebesar 39 persen dan responden berjenis kelamin perempuan berjumlah 62 orang dengan persentase sebesar 61 persen. Hal ini menunjukkan bahwa pengunjung Beachwalk kebanyakan perempuan. Perempuan memiliki kecenderungan untuk berjalan-jalan ke pusat perbelanjaan maupun pusat hiburan.

Tabel 1. menunjukkan bahwa jumlah responden yang berumur 18-25 tahun sebanyak 101 orang dengan persentase sebesar 99 persen, jumlah responden yang berumur 26-33 tahun sebanyak 1 orang dengan persentase sebesar 1 persen, jumlah responden yang berumur 34-41 tahun tidak ada responden dengan persentase sebesar 0 persen, jumlah responden yang berumur 42-50 tidak ada responden dengan persentase sebesar 0 persen. Hal ini menunjukkan bahwa pengunjung Beachwalk kebanyakan responden yang berumur 18-25 tahun, karena remaja yang berusia 18-25 tahun tersebut cenderung menyisihkan sebagian uangnya untuk berbelanja di Mall demi memenuhi kebutuhan mereka (Kusuma, 2011).

Tabel 1. menjelaskan bahwa jumlah responden berdasarkan pendidikan terakhir SMA sebanyak 86 orang dengan persentase sebesar 84 persen, responden berdasarkan pendidikan terakhir Diploma sebanyak 3 orang dengan persentase sebesar 3 persen, responden berdasarkan pendidikan terakhir S1 sebanyak 12 orang dengan persentase sebesar 12 persen, responden berdasarkan pendidikan terakhir lainnya sebanyak 1 orang dengan persentase sebesar 1 persen. Hal ini menunjukkan bahwa mayoritas responden dalam penelitian ini adalah 
yang memiliki tingkat pendidikan akhir yaitu SMA dengan jumlah sebanyak 86 orang dengan persentase sebesar 84 persen, karena seseorang yang berpendidikan SMA lebih suka berjalan - jalan ke pusat perbelanjaan dan pusat hiburan sehingga lebih sering berbelanja di Mall Beachwalk (Wahyudi, 2013)

Tabel 1. menunjukkan bahwa berdasarkan pekerjaan responden dapat diketahui bahwa jumlah responden dengan pekerjaan pelajar/mahasiswa sebanyak 94 orang dengan persentase sebesar 92 persen, jumlah responden dengan pekerjaan pegawai negeri sebanyak 1 orang dengan persentase sebesar 1 persen, jumlah responden dengan pekerjaan pegawai swasta sebanyak 4 orang dengan persentase sebesar 4 persen, jumlah responden dengan pekerjaan wiraswasta sebanyak 1 orang dengan persentase sebesar 1 persen, jumlah responden dengan pekerjaan lainnya sebanyak 2 orang dengan persentase sebesar 2 persen. Hal ini menunjukkan bahwa berdasarkan jenis pekerjaan responden dengan pekerjaan pelajar/mahasiswa memiliki jumlah paling tinggi yaitu sebanyak 94 orang dengan persentase sebesar 92 persen, karena responden yang memiliki jenis pekerjaan pelajar atau mahasiswa lebih suka refreshing ke pusat perbelanjaan modern dan lebih suka berbelanja di Mall Beachwalk.

Tabel 2.

Hasil Uji Validitas Instrumen Penelitian

\begin{tabular}{cccccc}
\hline No & Variabel & $\begin{array}{c}\text { Item } \\
\text { Pertanyaan }\end{array}$ & $\begin{array}{c}\text { Korelasi } \\
\text { item }\end{array}$ & Sig.(2-tailed) & Keterangan \\
\hline 1. & Store & X1 & 0,912 & 0,000 & Valid \\
& Atmosphere & X2 & 0,918 & 0,000 & Valid \\
(X) & X3 & 0,866 & 0,000 & Valid \\
& X4 & 0,877 & 0,000 & Valid \\
& X5 & 0,936 & 0,000 & Valid \\
& X6 & 0,947 & 0,000 & Valid \\
& X7 & 0,848 & 0,000 & Valid \\
& X8 & 0,917 & 0,000 & Valid \\
& M1 & 0,920 & 0,000 & Valid \\
& M2 & 0,931 & 0,000 & Valid \\
& Mositive & M4 & 0,899 & 0,000 & Valid \\
Emotion & M5 & 0,953 & 0,000 & Valid \\
(M) & & & 0,000 & Valid \\
& & Y1 & 0,810 & 0,000 & Valid \\
& Y2 & 0,897 & 0,000 & Valid \\
& Y3 & 0,897 & 0,000 & Valid \\
& Impulse & & 0,907 & 0,000 & Valid \\
buying & & & & \\
(Y) & & & &
\end{tabular}

Sumber: Data diolah, 2019

Hasil uji validitas pada Tabel 2. menunjukkan bahwa seluruh instrumen penelitian yang digunakan untuk mengukur variabel store atmosphere, positive emotion, dan Impulse buying memiliki nilai koefisien korelasi dengan skor total seluruh item pernyataan lebih besar dari 0,30 dengan signifikansi kurang dari 0,05 . Hal ini menunjukkan bahwa butir-butir pernyataan dalam instrument penelitian tersebut valid dan layak digunakan sebagai instrument penelitian.

Uji Reliabilitas terhadap instrumen penelitian ini menggunakan nilai Alpha 
Cronbach, yakni untuk mengetahui unidimensionalitas butir-butir pernyataan terhadap variabel yang diteliti (Store atmosphere, Positive emotion, dan Impulse buying). Nilai Alpha Cronbach dinyatakan reliabel jika nilainya lebih besar atau sama dengan 0,60. Rekapitulasi hasil uji reliabilitas instrumen penelitian dapat dilihat pada Tabel 3 .

Tabel 3.

Hasil Uji Reliabilitas Instrumen Peneitian

\begin{tabular}{cccc}
\hline No & Variabel & Cronbach'sAlpha & Keterangan \\
\hline 1. & Store Atmosphere & 0,966 & Reliabel \\
2. & Positive Emotion & 0,956 & Reliabel \\
3. & Impulse buying & 0,898 & Reliabel \\
\hline
\end{tabular}

Sumber : Data primer diolah, 2019

Hasil uji reliabilitas yang disajikan dalam Tabel 3. menunjukkan bahwa seluruh instrumen penelitian memiliki koefisien Cronbach's Alpha lebih dari 0,60. Jadi dapat dinyatakan bahwa seluruh variabel telah memenuhi syarat reliabilitas sehingga dapat digunakan untuk melakukan penelitian.

Tabel 4. menunjukkan bahwa masing-masing indikator memiliki nilai ratarata antara 3,56 sampai dengan 4,13. Semua indikator telah dinilai baik oleh responden karena rata-ratanya terletak antara 3,40 dan 4,19. Secara keseluruhan, nilai rata-ratanya adalah 3,87 yang berarti variabel store atmosphere juga dinilai baik. Indikator yang memiliki nilai rata-rata terttinggi adalah Beachwalk memiliki beragam produk dengan rata-rata 4,13, dan yang terendah adalah Beachwalk memiliki karyawan yang berpengetahuan luas dengan rata-rata 3,56

Penilaian responden terhadap indikator-indikator dari variable store atmosphere, jawaban paling besar dari responden ditunjukkan pada indikator dengan nilai skor rata-rata sebesar 4,13. Nilai skor rata-rata paling kecil ditunjukkan pada indikator daya tahan dengan nilai 3,56. Melihat data keseluruhan dari variabel store atmosphere, dapat ditentukan nilai skor rata-rata total sebesar 3,87, sehingga dapat dinyatakan bahwa secara umum responden memiliki persepsi baik terhadap store atmosphere di Beachwalk.

Variabel positive emotion dalam penelitian ini merupakan variabel mediasi yang diukur dengan menggunakan 5 pernyataan yang berhubungan dengan positive emotion di Beachwalk. Secara rinci hasil penelitian mengenai persepsi responden terhadap variabel positive emotion disajikan pada Tabel 5.

Penilaian responden terhadap indikator-indikator dari variabel positive emotion. Indikator terkait "Saya merasa puas saat berbelanja di Beachwalk "nilai skor rata-rata paling besar yaitu sebesar 4,03. Nilai skor rata - rata paling kecil ditunjukkan pada indikator "Saya merasa bangga saat berbelanja di Beachwalk", dengan rata-rata skor sebesar 3,66. Melihat data keseluruhan dari variabel positive emotion, dapat ditentukan nilai skor rata-rata total sebesar 3,85 sehingga dapat dinyatakan bahwa secara umum responden memiliki persepsi baik terhadap positive emotion yang terjadi di Beachwalk . 
Tabel 4.

Penilaian Responden terhadap variable Store Atmosphere

\begin{tabular}{|c|c|c|c|c|c|c|c|c|}
\hline No & Pernyataan & $\begin{array}{c}\text { STS } \\
1\end{array}$ & $\begin{array}{c}\text { TS } \\
2 \\
\end{array}$ & $\begin{array}{c}\text { CS } \\
3\end{array}$ & $\begin{array}{l}\mathbf{S} \\
4 \\
\end{array}$ & $\begin{array}{c}\text { SS } \\
5\end{array}$ & $\begin{array}{c}\text { Rata - } \\
\text { rata }\end{array}$ & Ket \\
\hline 1 & $\begin{array}{l}\text { Beachwalk memiliki musik yang } \\
\text { menyenangkan }\end{array}$ & 2 & 1 & 22 & 55 & 22 & 3.92 & Baik \\
\hline 2 & $\begin{array}{l}\text { Beachwalk memiliki aroma yang } \\
\text { menyenangkan }\end{array}$ & 2 & 4 & 26 & 54 & 16 & 3.76 & Baik \\
\hline 3 & $\begin{array}{l}\text { Pencahayaan di beachwalk yang } \\
\text { nyaman }\end{array}$ & 2 & 4 & 16 & 42 & 38 & 4.08 & Baik \\
\hline 4 & Beachwalk memiliki beragam produk & 2 & 1 & 18 & 42 & 39 & 4.13 & Baik \\
\hline 5 & $\begin{array}{l}\text { Sangat gampang mencari barang di } \\
\text { Beachwalk }\end{array}$ & 2 & 5 & 20 & 44 & 31 & 3.95 & Baik \\
\hline 6 & $\begin{array}{l}\text { Beachwalk memiliki karyawan yang } \\
\text { berpengetahuan luas }\end{array}$ & 2 & 5 & 37 & 50 & 8 & 3.56 & Baik \\
\hline 7 & $\begin{array}{l}\text { Beachwalk memiliki karyawan yang } \\
\text { sangat membantu }\end{array}$ & 2 & 2 & 27 & 52 & 19 & 3.82 & Baik \\
\hline 8 & $\begin{array}{l}\text { Beachwalk memiliki karyawan yang } \\
\text { ramah }\end{array}$ & 2 & 1 & 35 & 52 & 12 & 3.70 & Baik \\
\hline \multicolumn{7}{|c|}{ Skor rata- rata variabel store atmosphere } & 3.87 & Baik \\
\hline
\end{tabular}

Tabel 5.

Penilaian Responden terhadap variable Positive Emotion

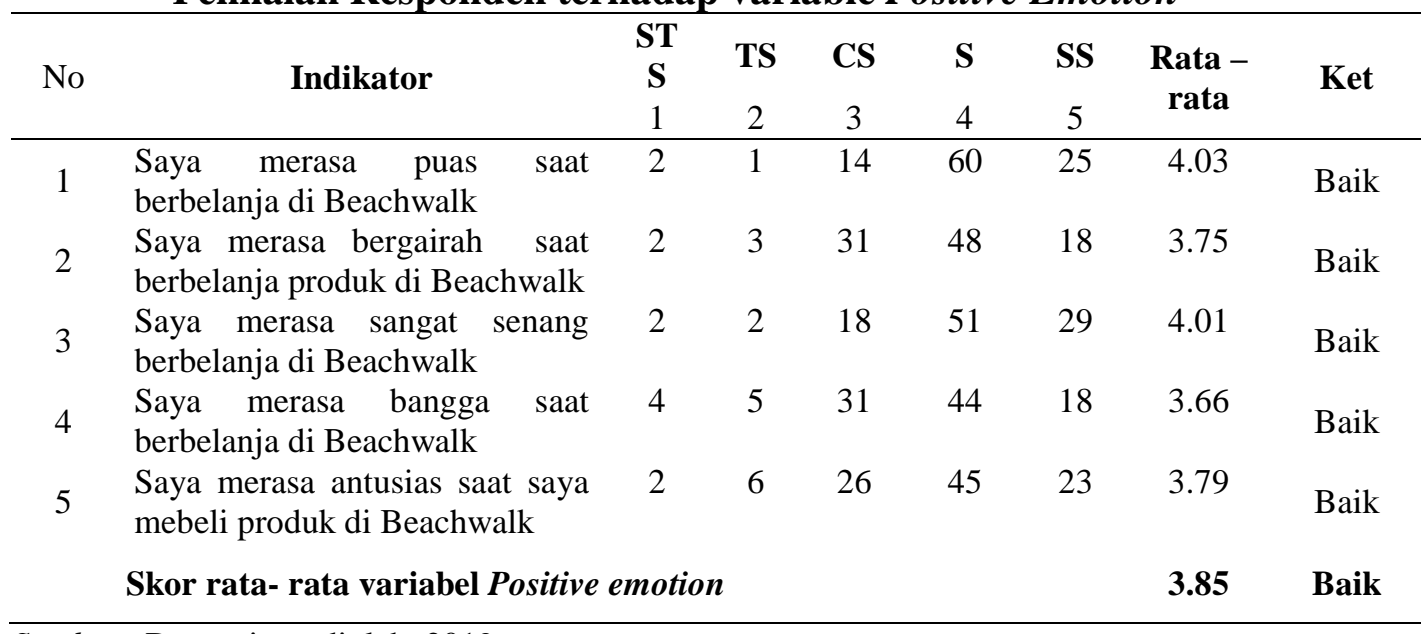

Sumber: Data primer diolah, 2019

Variabel terikat dalam penelitian ini diukur dengan menggunakan 4 pernyataan yang berhubungan dengan impulse buying yang terjadi di Beachwalk. Secara rinci hasil penelitian mengenai persepsi responden terhadap variabel 
impulse buying disajikan pada Tabel 6. berikut.

Tabel 6.

Penilaian Responden terhadap variable Impulse buying

\begin{tabular}{|c|c|c|c|c|c|c|c|c|}
\hline \multirow{2}{*}{ No } & Indikator & STS & TS & CS & $\mathbf{S}$ & SS & \multirow{2}{*}{$\begin{array}{l}\text { Rata } \\
\text { - rata }\end{array}$} & \multirow{2}{*}{ Ket } \\
\hline & & 1 & 2 & 3 & 4 & 5 & & \\
\hline 1 & $\begin{array}{l}\text { Saya membeli } \text { barang secara } \\
\text { spontan saat } \\
\text { Beachwalk }\end{array}$ & 3 & 9 & 26 & 44 & 20 & 3.68 & Baik \\
\hline 2 & $\begin{array}{l}\text { Jika saya melihat sesuatu yang } \\
\text { saya inginkan, saya membelinya }\end{array}$ & 3 & 5 & 23 & 44 & 27 & 3.85 & Baik \\
\hline 3 & $\begin{array}{l}\text { Saya tiba-tiba terdorong untuk } \\
\text { membeli sesuatu dan saya } \\
\text { membelinya }\end{array}$ & 1 & 7 & 33 & 45 & 16 & 3.67 & Baik \\
\hline 4 & $\begin{array}{l}\text { Saya membeli barang yang tidak } \\
\text { saya rencanakan sebelumnya }\end{array}$ & 3 & 8 & 33 & 31 & 27 & 3.70 & Baik \\
\hline & Skor rata- rata variabel impulse & buying & & & & & 3,72 & Baik \\
\hline
\end{tabular}

Penilaian responden terhadap indikator-indikator dari variabel impulse buying. Indikator terkait "Jika saya melihat sesuatu yang saya inginkan, saya membelinya" nilai skor rata-rata paling besar yaitu sebesar 3,85. Nilai skor rata rata paling kecil ditunjukkan pada indikator "Saya tiba-tiba terdorong untuk membeli sesuatu dan saya membelinya", dengan rata-rata skor sebesar 3,67. Melihat data keseluruhan dari variabel impulse buying, dapat ditentukan nilai skor rata-rata total sebesar 3,72 sehingga dapat dinyatakan bahwa secara umum responden memiliki persepsi baik terhadap impulse buying di Beachwalk.

Uji normalitas bertujuan untuk menguji apakah dalam residual dari model regresi yang dibuat berdistribusi normal atau tidak. Regresi yang baik memiliki distribusi normal. Uji yang dapat digunkan adalah Uji Kolmogrov Smirnov. Data dinyatakan berdistribusi normal jika taraf signifikansi lebih besar dari 0,05.

Berdasarkan Tabel 7. Hasil Uji Normalitas Persamaan Regresi 1 dari uji Kolmogorov Smirnov Z menunjuk nilai sebesar 1,097 dengan signifikansi sebesar 0,180 . Nilai signifikansi yang lebih besar dari 0,05 menunjukkan bahwa data sudah terdistribusi normal.

Berdasarkan Tabel 7. Hasil Uji Normalitas Persamaan Regresi 2 dari uji Kolmogorov Smirnov Z menunjuk nilai sebesar 1,273 dengan signifikansi sebesar 0,078. Nilai signifikansi yang lebih besar dari 0,05 menunjukkan bahwa data sudah terdistribusi normal.

Tabel 7.

Hasil Uji Normalitas Persamaan Regresi 1 dan 2

\begin{tabular}{lcc}
\hline & \multicolumn{2}{c}{ Unstandardized Residual } \\
& $\begin{array}{c}\text { Uji Normalitas Persamaan } \\
\text { Regresi 1 }\end{array}$ & $\begin{array}{c}\text { Uji Normalitas } \\
\text { Persamaan Regresi 2 }\end{array}$ \\
\hline $\mathrm{N}$ & 102 & 102 \\
Kolmogorov-Smirnov $Z$ & 1,097 & 1,273 \\
Asymp.Sig.(2-tailed) & 0,180 & 0,078 \\
\hline
\end{tabular}

Sumber : Data primer diolah, 2019 
Uji heteroskedastisitas bertujuan menguji apakah model regresi terjadi ketidaksamaan varians dari residual satu pengamatan ke pengamatan yang lain. Model regresi yang baik adalah yang tidak mengandung gejala heteroskedastisitas atau mempunyai varians yang homogen. Pengujian ini dilakukan dengan uji Glejser. Tingkat signifikansi dalam uji ini sebesar 0,05, apabila tingkat signifikansi berada di atas 0,05 maka model regresi ini bebas dari masalah heteroskedastisitas. Hasil dari uji ini dapat dilihat dari Tabel 8. berikut :

Tabel 8.

Hasil Uji Heteroskedastisitas Persamaan Regresi 1 dan 2 Hasil Uji Heteroskedastisitas Hasil Uji Heteroskedastisitas Persamaan Regresi $1 \quad$ Persamaan Regresi 2

\begin{tabular}{lcccc}
\hline Variabel bebas & $\mathrm{t}$ hitung & Sig & $\mathrm{t}$ hitung & Sig \\
Store Atmosphere & 0,710 & 0,479 & 1,713 & 0,090 \\
Positive Emotion & & & $-1,904$ & 0,060 \\
\hline
\end{tabular}

Sumber : Data primer diolah, 2019

Berdasarkan Tabel 8. Hasil Uji Heteroskedastisitas Persamaan Regresi 1 terlihat bahwa tidak ada pengaruh signifikan variabel bebas Store atmosphere terhadap Absolut residual (Abres1). Nilai signifikansi uji t di atas 0,05 menunjukkan data penelitian ini bebas dari heteroskedastisitas.

Pada Tabel 8. Hasil Uji Heteroskedastisitas Persamaan Regresi 2 dapat dilihat bahwa nilai signifikansi dari variabel Store atmosphere, dan Positive emotion, masing-masing sebesar 0,090 dan 0,060. Nilai tersebut lebih besar dari 0,05 yang berarti tidak terdapat pengaruh antara variabel bebas terhadap absolute residual (Abres 2). Dengan demikian, model yang dibuat tidak mengandung gejala heteroskedastisitas.

Uji linearitas digunakan untuk mengetahui pola hubungan antara variabel bebas dengan variabel terikat, mempunyai hubungan yang linear atau tidak secara signifikan. Nilai Sig. Linearity menunjukkan sejauh mana variabel bebas berbanding tepat di garis lurus. Apabila nilai Sig. Linearity lebih kecil dari tingkat signifikansi 0,05, maka regresi linier dapat dipergunakan untuk menjelaskan pengaruh antara variabel-variabel yang ada. Hasil dari Uji Linieritas Ini dapat dilihat dari Tabel 9.

Hasil uji linieritas nampak bahwa hubungan variabel bebas Store atmosphere, variabel intervening emosi positif dan variabel terikat Impulse buying dikatakan linier karena tingkat signifikansinya lebih kecil dari 5 persen $(\mathrm{p}<0,05)$, dengan demikian terbukti bahwa data yang digunakan memenuhi persyaratan linieritas.

Penelitian ini menggunakan teknik analisis jalur (Path Analysis). Analisis dilakukan dengan menggunakan 2 persamaan regresi. Persamaan Regresi 1 digunakan untuk mengetahui pengaruh Store Atmosphere (X) terhadap Positive Emotin (M). Persamaan Regresi 2 digunakan untuk mengetahui pengaruh Store Atmosphere (X) dan Positive Emotion (M) terahadap Impuse Buying (Y). 
Tabel 9.

Hasil Uji Linieritas

\begin{tabular}{|c|c|c|c|c|c|}
\hline No & Hubungan Antar Variabel & $\begin{array}{l}\text { Kriteria } \\
\text { Pengujian }\end{array}$ & $\begin{array}{l}\text { Hasil } \\
\text { Pengujian } \\
\text { F }\end{array}$ & Sig & Ket \\
\hline 1. & $\begin{array}{l}\text { Store Atmosphere }(\mathrm{Y}) \\
\text { Positive Emotion }(\mathrm{M})\end{array}$ & Linearity & 610,551 & 0,000 & Linear \\
\hline 2. & $\begin{array}{l}\text { Store Atmosphere }(\mathrm{Y}) \longrightarrow \\
\text { Impluse buyng }(\mathrm{Y})\end{array}$ & Linearity & 194,722 & 0,000 & Linear \\
\hline 3. & $\begin{array}{l}\text { Positive emotion }(\mathrm{M}) \longrightarrow \\
\text { Impulse buying }(\mathrm{Y})\end{array}$ & Linearity & 204,611 & 0,000 & Linear \\
\hline
\end{tabular}

Sumber : Data primer diolah, 2019

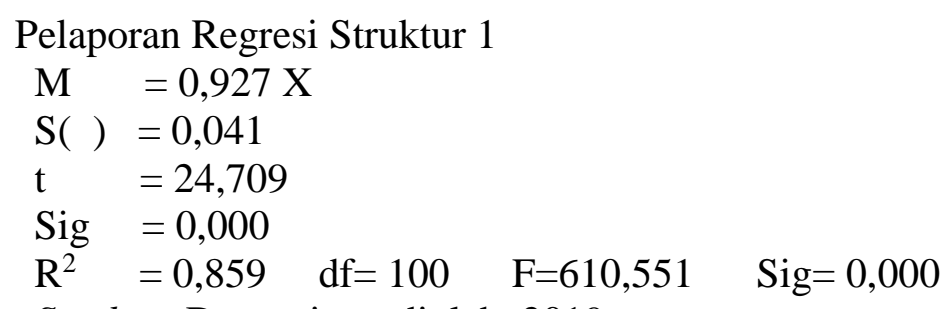

Sumber: Data primer diolah, 2019

Pelaporan Regresi Struktur 2

$$
\begin{aligned}
& \mathrm{Y}=0,377 \mathrm{X}+0,470 \mathrm{M} \\
& S(\beta)=(0,175)(0,158) \\
& \mathrm{t} \quad=(2,537)(3,158) \\
& \text { Sig }=(0,013)(0,002) \\
& R^{2}=0,692 \quad d f=99 \quad F=111,086 \quad \text { Sig }=0,000
\end{aligned}
$$

Berdasarkan Pelaporan Regresi Struktur 1 seperti yang terdapat di lampiran

6 , dapat diketahui bahwa nilai koefisien regresi variabel bernilai positif dengan nilai signifikansi uji t kurang dari 0,05 . Hal ini menunjukkan bahwa variabel Store atmosphere memiliki pengaruh positif yang signifikan terhadap variabel Positive emotion. Besarnya pengaruh variabel bebas terhadap variabel terikat yang ditunjukkan oleh nilai determinasi total ( $\mathrm{R}$ Square) sebesar 0,859 mempunyai arti bahwa sebesar $85,9 \%$ variasi Positive emotion dipengaruhi oleh variasi Store atmosphere, sedangkan sisanya sebesar 14,1\% dijelaskan oleh faktor lain yang tidak dimasukkan ke dalam model.

Berdasarkan Pelaporan Regresi Struktur 2 seperti yang terdapat di lampiran

6 , dapat diketahui bahwa nilai koefisien regresi masing-masing variabel bebas bernilai positif dengan nilai signifikansi uji t kurang dari 0,05. Hal ini menunjukkan bahwa semua variabel bebas memiliki pengaruh positif yang signifikan terhadap variabel terikat. Besarnya pengaruh variabel bebas terhadap variabel terikat yang ditunjukkan oleh nilai determinasi total (R Square) sebesar 0,692 mempunyai arti bahwa sebesar 69,2 persen variasi Impulse buying dipengaruhi oleh variasi store atmosphere dan positive emotion, sedangkan 
sisanya sebesar 30,8 persen dijelaskan oleh faktor lain yang tidak dimasukkan ke dalam model.

Tabel 10.

Pengaruh Langsung Variabel Penelitian

\begin{tabular}{llcccc}
\hline Hubungan Variabel & $\begin{array}{c}\text { Koefisien } \\
\text { regresi } \\
\text { Standar }\end{array}$ & SE & T & Sig \\
\hline $\begin{array}{l}\text { Store Atmosphere } \\
\begin{array}{l}\text { Positive Emotion } \\
\text { Store Atmosphere }\end{array}\end{array}$ & 0,927 & 0,041 & 24,709 & 0,000 \\
$\begin{array}{l}\text { Impulse buying } \\
\text { Positive emotion } \\
\text { Impulse buying }\end{array}$ & $\longrightarrow$ & 0,377 & 0,175 & 2,537 & 0,013 \\
\hline
\end{tabular}

Sumber: Data primer diolah, 2019

Berdasarkan Tabel 10. diatas, dapat diketahui bahwa Store atmosphere berpengaruh langsung terhadap Positive emotion, yaitu dengan signifikansinya sebesar 0,000 atau kurang dari satu persen. Namun variabel Store atmosphere tidak berpengaruh nyata terhadap Impulse buying dengan signifikansi sebesar 0,013. Sedangkan variabel Positive emotion berpengaruh langsung terhadap Impulse buying, yaitu dengan signifikansinya sebesar 0,002 atau kurang dari satu persen.

Besarnya nilai $\mathrm{e}_{1}=\sqrt{ }(1-0,859)=0,375$ dan besarnya nilai $\mathrm{e}_{2}=\sqrt{ }(1-0,692)$ $=0,555$. Koefisen determinasi total persamaan struktural $R_{m}^{2}=1-\left(0,375^{2} X\right.$ $\left.0,555^{2}\right)=0,960$ mempunyai arti bahwa sebesar 96 persen informasi yang terkandung oleh model yang dibentuk, sedangkan sisanya yaitu 4 persen dijelaskan oleh variabel di luar model yang dibentuk.

Tabel 11.

Pengaruh Langsung, Pengaruh Tidak Langsung serta Pengaruh Total

\begin{tabular}{|c|c|c|c|}
\hline Pengaruh Variabel & $\begin{array}{l}\text { Pengaruh } \\
\text { Langsung }\end{array}$ & $\begin{array}{l}\text { Pengaruh Tidak } \\
\text { langsung }\end{array}$ & Pengaruh Total \\
\hline $\begin{array}{l}\text { Store Atmosphere } \rightarrow \\
\text { Positive emotion }\end{array}$ & 0,927 & - & 0,927 \\
\hline $\begin{array}{l}\text { Positive Emotion } \rightarrow \\
\text { impuse buying }\end{array}$ & 0,470 & - & 0,470 \\
\hline $\begin{array}{l}\text { Store Atmosphere } \rightarrow \\
\text { Impulse buying }\end{array}$ & 0,377 & 0,350 & 0,727 \\
\hline
\end{tabular}

Sumber :Data primer, 2019

Tabel 11. menunjukkan bahwa Store atmosphere berpengaruh langsung terhadap Impulse buying sebesar 0,377 persen, dengan dimediasi oleh variabel Positive emotion maka didapatkan pengaruh tidak langsung sebesar 0,350 persen, dan pengaruh total sebesar 0,727 persen. Hasil tersebut menunjukkan bahwa Positive emotion memediasi pengaruh Store atmosphere terhadap Impulse buying secara parsial. 
Uji sobel digunakan untuk menguji kekuatan pengaruh tidak langsung variabel Store atmosphere (X) ke variabel Impulse buying (Y) melalui variabel Positive emotion (M). Berdasarkan hasil analisis pada Lampiran 10 diketahui nilai $\mathrm{a}=0,927 ; \mathrm{sa}=0,041 ; \mathrm{b}=0,47 ; \mathrm{sb}=0,158$, dengan menggunakan rumus sobel diatas didapat nilai $\mathrm{Z}$ sebesar 2,9464.

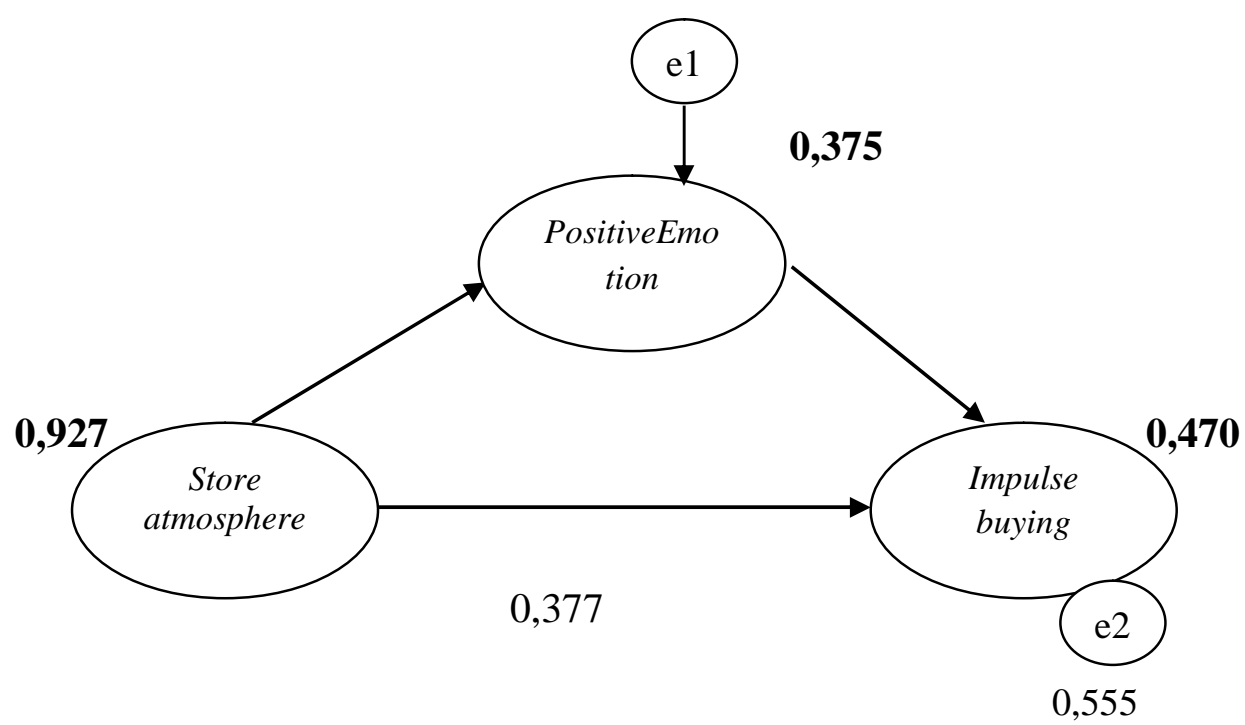

\section{Gambar 3. Diagram Jalur Pengaruh Store Atmosphere terhadap Impulse buying melalui Positive emotion}

Oleh karena z hitung sebesar 2,9464 lebih besar dari 1,96 berarti Positive emotion merupakan variabel yang memediasi pengaruh Store atmosphere terhadap Impulse buying.

Penelitian ini terdiri dari 102 responden yang merupakan konsumen yang pernah berbelanja di Beachwalk responden dalam penelitian ini mayoritas perempuan berjumlah 62 orang dengan persentase 60,8\%. Berdasarkan usia, mayoritas responden berusia 18-25 tahun 101 orang dengan persentase 99,02\%. Menurut jenjang pendidikan, mayoritas responden berpendidikan SMA sebanyak 86 orang dengan presentase $84,32 \%$. Responden dalam penelitian ini mayoritas pelajar / mahasiswa sebanyak 94 orang responden dengan persentase $92,16 \%$.

Hasil analisis meunjukkan Pengaruh antara store atmosphere terhadap positive emotion telah diuji dalam penelitian ini, dimana nilai koefisien beta diperoleh sebesar 0,927 dengan tingkat signifikansi $0,000 \leq 0,05$ sehingga $\mathrm{H} 0$ ditolak dan $\mathrm{H}_{1}$ diterima, yang mengindikasikan bahwa store atmosphere berpengaruh positif dan signifikan terhadap positive emotion. Hasil tersebut menunjukkan bahwa semakin baik store atmosphere di beachwalk, maka semakin sering konsumen merasakan positive emotion saat berbelanja di Beachwalk.

Pengaruh antara positive emotion terhadap impulse buying dalam penelitian ini diperoleh nilai koefisien beta sebesar 0,470 dengan tingkat signifikansi 0,002 $\leq 0,05$ sehingga $\mathrm{H}_{0}$ ditolak dan $\mathrm{H}_{2}$ diterima, yang mengindikasikan bahwa positive 
emotion berpengaruh positif dan signifikan terhadap impulse buying. Hasil tersebut menunjukkan bahwa semakin tinggi positive emotion yang dirasakan konsumen saat berbelanja di Beachwalk, maka semakin tinggi pula impulse buying yang terjadi di Beachwalk.

Pengaruh antara store atmosphere terhadap impulse buying dalam penelitian ini diperoleh nilai koefisien beta sebesar 0,377 dengan tingkat signifikansi 0,013 $\leq 0,05$ sehingga $\mathrm{H}_{0}$ ditolak dan $\mathrm{H}_{3}$ diterima, yang mengindikasikan bahwa store atmosphere berpengaruh positif dan signifikan terhadap impulse buying. Hasil tersebut menunjukkan bahwa semakin baik store atmosphere di Beachwalk, maka semakin tinggi impulse buying yang terjadi saat konsumen berbelanja di Beachwalk.

Peran positive emotion memediasi pengaruh store atmosphere terhadap impulse buying di Beachwalk telah diuji dalam penelitian ini. Hasil uji pengaruh store atmosphere terhadap impulse buying semula bernilai 0,377. Kemudian setelah adanya positive emotion sebagai variabel mediasi, nilai pada pengaruh store atmosphere terhadap impulse buying meningkat menjadi sebesar 0,727. Uji sobel yang telah dihitung memperkuat hasil tersebut dengan nilai koefisien $\mathrm{z}$ yang diperoleh adalah 2,9464>1,96 sehingga $\mathrm{H}_{0}$ ditolak dan $\mathrm{H}_{4}$ diterima, yang mengindikasikan bahwa positive emotion memediasi pengaruh store atmosphere terhadap impulse buying. Hasil tersebut menunjukkan bahwa positive emotion dinilai mampu memediasi pengaruh store atmosphere terhadap impulse buying di Beachwalk.

\section{SIMPULAN}

Berdasarkan hasil analisis penelitian dan hasil pembahasan, maka dapat ditarik beberapa kesimpulan yaitu store atmosphere berpengaruh positif dan signifikan terhadap Positive emotion. Artinya semakin baik Store atmosphere di Beachwalk, maka Positive emotion yang dirasakan oleh konsumen akan meningkat juga. Positive emotion berpengaruh positif dan signifikan terhadap Impluse buying. Artinya semakin sering konsumen merasakan Positive emotion di Beachwalk, maka konsumen lebih sering atau meningkat melakukan Impluse buying saat berbelanja di Beachwalk. Konsumen yang merasakan senang, bahagia, nyaman saat berbelanja di Beachwalk sehingga akan mudah terdorong untuk melakukan Impluse buying, hal ini juga akan meningkatakan penjualan di Beachwalk. Store atmosphere berpengaruh positif dan signifikan terhadap Impluse buying. Artinya semakin baik Store atmosphere, maka Impluse buying yang dilakukan kosumen akan meningkat. Peran Positive emotion mampu memediasi secara signifikan hubungan Store atmosphere dengan Impluse buying. Artinya Positive emotion dinilai mampu memediasi hubungan Store atmosphere dengan Impluse buying di Beachwalk dilihat dari hasil $\mathrm{Z}$ uji sobel yang menyatakan lebih besar dari 1,96.

Saran bagi Beachwalk yaitu Karyawan Beachwalk memiliki karyawan yang kurang pengetahuannya tentang informasi produk, maka dari itu karyawan sebaikknya karyawan diberikan informasi oleh manajernya berupa buku yang berisi produk beserta fungsi dan harganya, dengan begitu karyawan harus 
membaca, memahami, dan mengingat produk yang dijual, sehingga pengetahuan karyawan mengenai produk bisa lebih luas. Konsumen tidak merasa bangga saat berbelanja di Beachwalk, maka dari itu karyawan di Beachwalk harus meningkatakan pelayanan dan memberikan penwaran khusus seperti diskon, bonus sehingga konsumen akan meningatakan rasa bangga konsumen karena selain konsumen membeli brand produk yang terkenal tetap harganya juga terjangkau. Konsumen tidak secara spontan saat berbelanja di Beachwalk, maka dari itu Beachwak harus tetap memperhatikan store atmosphere harus dengan konsep ramah lingkungan, sehingga dengan begitu konsumen yang awalnya tidak ingin membeli, maka dengan perhatian yang lebih terhadap store atmosphere maka akan mendorong konsumen lebih sering melakukan impulse buying.

\section{REFERENSI}

Adiputra, E. (2015). Perilaku Pembelian Tidak Terencana (Impulse Buying) Di Pusat Perbenjaan Modern Di Surabaya. An-Nisbah: Jurnal Ekonomi Syariah. 1(2),155-180.

Ahmad, M., Ali, H., Malik, M., Humayun, A., \& Ahmad, S. (2019). Factors Affecting Impulsive Buying Behavior with Mediating role of Positive Mood: An Empirical Study. European Online Journal of Natural and Social Sciences. 8(1), 17-35.

Ajzen, \& Fisbhen. (2013). The theory of planned behavior. Jurnal Organizational Behavior and Human Decision Processes.50(2), 179-211.

Andani, K., \& Wahyono. (2018). Management Analysis Journal. Management Analysis Journal. 7(4).

Andriyanto, D. S., Suyadi, I., \& Fanani, D. (2016). Pengaruh Fashion Involvement Dan Positive Emotion Terhadap Impulse Buying (Survey pada Warga Kelurahan Tulusrejo Kecamatan Lowokwaru Kota Malang). Jurnal Administrasi Bisnis S1 Universitas Brawijaya. 31(1), 42-49.

Asrinta, P. S. (2018). The Influence of Sales Promotion and Store Atmosphere towards Impulse Buying with Shopping Emotion as Intervening Variable. Journal of Research in Management.1(2). 23-33.

Dewi, K., \& Giantari, I. G. A. K. (2015). Peran Emosi Positif Dalam Memediasi Store Atmosphere Terhadap Pembelian Impulsif (Studi Pada Konsumen Matahari Department Store Duta Plaza Denpasar). E-Jurnal Manajemen Universitas Udayana.4(12), 4419-4448.

Hasanah, M. A., Hadi, P., \& Ridwan, H. (2017). The Role of The Store Atmosphere To Impulsive Purchasing (Study in Matahari Cilandak Town Square ). FEBI Management and Business Review (AMBR). 2(1), 80-94. 
Idedhyana, I. B. (2016). Perancangan tapak pada mall Kuta beachwalk memadukan alam lingkungan dan kearifan lokal. Jurnal Teknik Gradien.8(2). 116-132.

Ismayuni, I., \& Saraswati, T. G. (2015). Emosi Positif , Keterlibatan Fashion , Kecenderungan Konsumsi Hedonis Terhadap Perilaku Pembelian Impulsif Pada Konsumen Positive Emotion, Fashion Involvement, Hedonic Consumption Tedency To Impulsive Buying Behaviour on Consumers Nike . E-Proceeding of Management,.2(3), 3733-3741.

Kurniawan, D., \& Kunto, S. Y. (2013). Pengaruh Promosi Dan Store Atmosphere Terhadap Impulse Buying Dengan Shopping Emotion Sebagai Variabel Intervening Studi Kasus Di Matahari Department Store Cabang Supermall Surabaya. Jurnal Manajemen Pemasaran Petra.1(2), 1-8.

Kusuma, L. (2011). Pengeluaran Pulsa Lebih Besar daripada Beli Buku Kuliah. Diunduh dari Kompasiana website: 4kusuma/550192fca3331198145116db/pengeluaran-pulsa-lebih-besardaripada-beli-buku-kuliah

Leba, E. (2015). Pengaruh atmosfer gerai dan promosi terhadap pembelian impulsif yang dimediasi emosi positif. Jurnal Ilmu Dan Riset Manajemen.4(1), 1-17.

Liaw, Gou-Fong. (2007). The Influence of Multiple Store Environment Cues on Shopping Mood and Patronage Satisfaction. 7th Global Conference on Bussines and Economics. 1-21.

Margana, C., \& Setiawan, P. Y. (2014). Pengaruh Stimulus Lingkungan Toko Terhadap Perilaku Pembelian Tidak Terencana Yang Dimediasi Oleh Emosi Positif. E-Jurnal Manajemen Universitas Udayana. 3(9), 2615-2632.

Maulana, R. I. (2018). Promosi dan Store Atmosphere Terhadap Shopping Emotion dan Impulse Buying. Jurnal Ecodemica.2(2), 213-225.

Negara, A. A. B. J., \& Kusumadewi, N. M. W. (2018). Buying Yang Dimediasi Emosi Positif. E-Jurnal Manajemen Unud.7(7), 3944-3973.

Nindyakirana, R. H., \& Maftukhah, I. (2016). Lingkungan toko dan dampaknya terhadap Impulse Buying. Management Analysis Journal. 5(4), 375-388.

Nofiawaty, \& Yuliandi, B. (2014). Pengaruh Store Atmosphere Terhadap Keputusan Pembelian Konsumen Pada Outlet Nyenyes Palembang. Jurnal Manajemen Dan Bisnis Sriwijaya.12(1), 55-73. 
Nurcaya, I. N., \& Rastini, N. M. (2018). Impulse Buying Behavior on Modern Retail. Udayana Journal of Social Sciencec and Humanities. Udayana Journal of Social Sciencec and Humanities. 2(2), 101-108.

Ompi, A. P., Sepang, J. L., Wenas, R. S., \& Sam. (2018). Analisis Faktor-Faktor Yang Menyebabkan Terjadinya Pembelian Impulsif Produk Fashion Di Outlet Cardinal Mega Mall Manado. Jurnal EMBA. 6(4), 2918-2927.

Putra, B. P., \& Mudiantono. (2014). Analisis Pengaruh Promosi , Emosi Positif Dan Store Environment Terhadap Perilaku Impulse Buying ( Studi Kasus Pada Pelanggan Swalayan Tong Hien di Kota Semarang). Diponegoro Journal Of Management.3(4), 1-11.

Rahmadana, Nur Maya Sari. (2016). Pengaruh Display Produk dan Suasana Toko Terhadap Pembelian Impulsif di Minimarket Eramart Cabang Lembuswana Samarinda. Journal Ilmu Administrasi Bisnis. 4(3), 683-697.

S.B.Hearth. (2014). The Impact of In-Store Enviroment on the Impulse buying Behaviour on at Supermarkets in Sri Lanka.Universitas Jayewardenepura.

Sari, D. R., \& Faisal, I. (2018). Pengaruh Price Discount, Bonus Pack, dan InStore Display terhadap Keputusan Impulse Buying pada Giant Ekstra Banjar. Jurnal Sains Manajemen Dan Kewirausahaan . 2(1), 51-60.

Sugiyono. (2014). Metode Penelitian Pendidikan Pendekatan Kuantitatif, Kualitatif, dan R\&D. Bandung: Alfabeta.

Sugiyono. (2016). Metode Penelitian Kuantitatif, Kualitatif, dan R\&D. Bandung: CV Alfabeta.

Sobel, M. E. (1982). Asymptotic Confidence Intervals for Indirect Effects in Structural Equation Models.In S. Leinhardt (Ed.), Sociological Methodology 1982. Washington DC: American Sociological Association.

Tirmizi, M. A., Rehman, K.-U., \& Saif, M. I. (2009). An Empirical Study of Consumer Impulse Buying Behavior in Local Markets. European Journal of Scientific Research.28(4), 522-532.

Utama, M. S. (2016).Aplikasi Analisis Kuantitatif. Denpasar:CV.Sastra Utama.

Wahyudi. (2013). Tinjauan Tentang Perilaku Konsumtif Remaja Pengunjung Mall Samarinda Central Plaza. E-Juornal Sosiatri - Sosiologi.1(4).

Winawati, N. F., \& Saino. (2015). Pengaruh Store Atmosphere Dan Promosi Penjualan Terhadap Impulse Buying Dengan Shopping Emotion Sebagai 
E-Jurnal Manajemen, Vol. 9, No. 3, 2020 : 884-903

Variabel Intervening (Studi Pada Konsumen Hypermart Ponorogo City Center ). Jurnal Pendidikan Tata Niaga.3(2), 1-15. 